Int. J. Electrochem. Sci., 16 (2021) Article ID: 210420

International Journal of

ELECTROCHEMICAL

SCIENCE

www.electrochemsci.org

\title{
A Simple Synthesis of Porous Titanium Dioxide Nanofibres with a Large Specific Surface Area by Electrospinning as High- Performance Anode Materials for Lithium-Ion Batteries
}

\author{
Manman Xia, Jun Li*, Ruyan Lei, Baige Yuan, Ying Zhang, Peng Zhao and Xiao Li \\ School of Materials Engineering, Shanghai University of Engineering Science, Shanghai 201620, \\ China \\ *E-mail: jacob_lijun@sues.edu.cn
}

doi: $10.20964 / 2021.04 .55$

Received: 18 December 2020 / Accepted: 29 January 2021 / Published: 28 February 2021

\begin{abstract}
Anatase titanium dioxide is considered a promising anode material for lithium-ion batteries (LIBs), however its application is restricted due to the poor $\mathrm{Li}^{+}$transport. Nano-crystallization and pore creation are regarded as two effective strategies for solving the above shortcomings. This study aims to realize the combination of the two strategies by synthesizing porous anatase $\mathrm{TiO}_{2}$ nanofibres by electrospinning with camphene as the pore-creating agent. Porous anatase $\mathrm{TiO}_{2}$ nanofibres as anode materials for LIBs demonstrated excellent electrochemical performance when a suitable content of camphene was added. The results indicated that a larger specific surface area $\left(72 \mathrm{~m}^{2} \cdot \mathrm{g}^{-1}\right)$ was obtained in anatase $\mathrm{TiO}_{2}$ nanofibres with $12 \mathrm{wt} . \%$ camphene than in those without camphene $\left(61 \mathrm{~m}^{2} \cdot \mathrm{g}^{-1}\right)$. The former exhibited a higher initial discharge specific capacity $\left(518.71 / 294.99 \mathrm{mAh} \cdot \mathrm{g}^{-1}\right)$ than the latter $\left(305.56 / 114.68 \mathrm{mAh} \cdot \mathrm{g}^{-}\right.$ $\left.{ }^{1}\right)$. Moreover, the former demonstrated outstanding cycle performance due to the higher retention rate of $21.7 \%$ obtained after 100 cycles. Meanwhile, an excellent rate performance was also achieved due to a larger average discharging specific capacity $\left(58.96 \mathrm{mAh} \cdot \mathrm{g}^{-1}\right)$ being when the current density increased from $0.5 \mathrm{C}$ to $10 \mathrm{C}$ and recovered to $0.5 \mathrm{C}\left(145.71 \mathrm{mAh} \cdot \mathrm{g}^{-1}\right)$. The improvement in electrochemical performance should be attributed to the low charge transfer resistance $\left(\mathrm{R}_{\mathrm{ct}}\right)$ and large transportation rate of $\mathrm{Li}^{+}$resulting from the obtained high specific surface area.
\end{abstract}

Keywords: Electrospinning, porous anatase titanium dioxide, Camphene, Lithium-ion battery anode

\section{$\underline{\text { FULL TEXT }}$}

(C) 2021 The Authors. Published by ESG (www.electrochemsci.org). This article is an open access article distributed under the terms and conditions of the Creative Commons Attribution license (http://creativecommons.org/licenses/by/4.0/). 